\title{
$\mathrm{XL}$. On the luminosity of gases through electrical discharges. Supplement to the paper on the nature of spectra
}

\section{Eilhard Wiedemann}

To cite this article: Eilhard Wiedemann (1879) XL. On the luminosity of gases through electrical discharges. Supplement to the paper on the nature of spectra, Philosophical Magazine Series 5, 7:43, 248-251, DOI: 10.1080/14786447908639601

To link to this article: http://dx.doi.org/10.1080/14786447908639601

曲 Published online: 13 May 2009.

Submit your article to this journal $[\pi$

Џll Article views: 2

Q View related articles $\sqsubset$ 


\section{[ 248 ]}

XI. On the Luminosity of Gases through Electrical Discharges. Supplement to the Paper on the Nature of Spectra. By Eilmard Wiedemañ *.

T $\mathrm{N}$ an investigation published in this Journal $\dagger \mathrm{I}$ expressed 1 the opinion that by the electric spark, independently of the temperature of a mixture of gases, certain particles are rendered luminous, and that the luminosity is not a direct consequence of a great rise of temperature, like the brightness of incandescent solids, for instance, or that of sodium vapour in a gas-flame. I have, on that account, compared the phenomenon in question to the phenomena of fuorescence.

New experiments have confirmed this view, and yielded the result, that a gas may become luminous, on electricity passing through it, while yet its temperature is far below $100^{\circ}$.

For the experiments a discharge-tube was used consisting, first, of a wider portion 30 millims. in diameter and 90 millims. in length, which was conically drawn out at its ends. To one end a glass bulb provided with a glass cock was fused, in the middle of which was an aluminium knob, serving as electrode; to the other end a capillary tube bent in the shape of a $U$, diameter 0.854 millim., height of the $U$ about 93 millims., was joined by fusion, to which was attached a glass bulb with cock and aluminium electrode.

The U-tube was placed in a calorimeter, which consisted of a brass tube filled with oil of turpentine into which a thermometer dipped, and was enclosed in a double-walled vessel filled with water. The waterworth of the entire calorimeter inclusive of the oil of turpentine, the thermometer, and the immersed portion of the U-tube, amounted in the experiments to 8.846 grams.

The discharge-tube was filled with air and exhausted (to about 3 millims.) till the entire wide tube was completely filled with continuous light when the discharges passed through it. A very feeble stratification appeared momentarily in isolated cases only. After the pressure was read off, the cock communicating with the air-pump was closed.

A Ruhmkorff induction-coil of medium size, with a mercury interruptor, served as the source of electricity. By a simple arrangement a black-writer was inserted, through a relais, in a second current-circuit, which marked the number of the closings of the Rubmkorff, and therefore also the number of the discharges through the Geissler tube.

* Translated from a separate impression, communicated by the Author, from Wiedemanu's Annalen, vi. pp. 298-302.

$\dagger$ Phil. Mag. Feb. 1879, pp. 77-95. 
The inductorium was excited by two Bunsen elements. The calorimetric determinations were carried out in the following manner:-First, for 5-10 minutes before the experiment the course of the thermometer was observed; then, exactly at the minute, the primary circuit of the inductorium was closed. When with the play of the interruptor a sufficient angmentation of the temperature of the calorimeter had taken place, the current-circuit was again opened, at a moment which was read off, and the course of the thermometer followed again during 5-10 minutes. From the rise of temperature which had taken place, corrected in the well-known manner, and from the number of the discharges, counted on the strip of paper of the marker, the quantity of heat generated at each single discharge in the capillary tube could be calculated. From this, and from the dimensions of the capillary tube, the temperature of the gas can be approximately ascertained, provided that its specific heat does not alter much with the temperature.

From the older experiments of $G$. Wiedemann and the newer ones of A. Naccari and Bellati, however, it follows that the quantity of heat generated in each cross section of a dischargetube at the passing of the discharge is independent of the magnitude of the section, and in very wide tubes is somewhat less. It thence follows, further, that the increments of temperature must be inversely proportional to the cross section, and so the increments of temperature of the gas in the wider tube can be calculated from those observed in the narrower one.

If $p$ is the pressure of the gas, $V$ the volume of the heated gas in the capillary tube below the surface of the oil of turpentine, $z$ the number of discharges in a minute, $Z$ the time, in minutes, during which the discharges pass through the gas, $t$ the corrected increase of temperature generated in the calorimeter, $c$ the specific heat of the gas, $s$ its specific gravity at $0^{\circ}, w$ the waterworth of the calorimeter, then the increment of temperature $\mathrm{T}$ of the gas, to be calculated from the above quantities, at each discharge in the capillary tube is very nearly

$$
\mathrm{T}=\frac{w t .760}{\mathrm{~V} \operatorname{sepZz}} *
$$

* For $c$ I have introduced the specific heat at a constant pressure, 0.237 . It might, howerer, be possible for the heating in a part, at least, of the capillary tube to take place at constant volume; the numbers found for $T$ and $\tau$ would then become $\frac{1}{4}$ higher. In face of this uncertainty the error vanishes completely which we have committed in putting for $s$ the specific gravity at $0^{\circ}$ and not that at the temperature of the experiment. 
Dividing $\mathrm{T}$ by the ratio of the cross section of the wider tube to that of the narrower (1232), we get the increment of temperature in the former,

$$
\tau=\frac{\mathrm{T}}{1232} \text {. }
$$

Of a whole series of experiments I give the following five, together with the values obtained from them for $\tau$ and $\mathrm{T}$ :-

\begin{tabular}{|c|c|c|c|c|c|c|}
\hline$p$. & $\begin{array}{c}\text { V. } \\
\text { cub. cent. }\end{array}$ & $z$. & z. & $t$. & T. & $\tau$. \\
\hline $3 \cdot 3$ & $0 \cdot 09774$ & 350 & 9 & $3 \cdot 93$ & 84340 & $68 \cdot 0$ \\
$3 \cdot 3$ & $"$ & 342 & 8 & $3 \cdot 24$ & 80130 & $65 \cdot 2$ \\
$3 \cdot 3$ & $"$ & 348 & 8 & 352 & 85560 & $69 \cdot 5$ \\
$2 \cdot 66$ & $"$ & 348 & 10 & 351 & 86660 & $70 \cdot 4$ \\
$2 \cdot 66$ & $"$ & 338 & 14 & $4 \cdot 35$ & 77250 & $62 \cdot 0$ \\
\hline
\end{tabular}

As the mean temperature of the gas, before the passing of the discharge, amounted to about $20^{\circ}$, the maximum temperature generated in the first tube was about $80-90^{\circ}$; and therewith the gas was brightly luminous.

It is necessary to remark that if alternating partial discharges take place, the above temperature is still too high; and so it is when the discharges do not take place momentarily, but last a certain time. Further, since the gas constantly becomes quite dark again between every two discharges, and shines as brightly after the first as after the later ones, the luminous appearances cannot be conditioned by heatings being accumulated by the successive discharges. The temperature $62-70^{\circ}$ is at all events not the lowest at which the gas appears luminous; for when the discharges of a Holtz machine were conducted through a discharge-tube precisely similar to that above described, the wider part of it appeared completely filled with light, while the light in the narrower part was much fainter than when the inductorium was employed. Exact calorimetric measurements are, in consequence of the inconsiderable production of heat, much more difficult to make with the former than with the latter.

The luminousness of the gas at so low a temperature during the passage of electricity proves, when viewed in connexion with the mechanical theory of gases, that the electric discharge, independently of an augmentation of the vis viva of the progressive motion of the molecules by temperature, calls forth a considerable heightening of the vis vira of the oscillatory motion of the ather envelopes.

To make use of the result here found for explaining what goes on in the discharges in gases, and the nature of the elec- 
tricity-motion, as well as for the application of electrical discharges to the study of the spectra of gases, is reserved for separate investigations. Meanwhile so much is eren now evident, that the different spectra in the parts of different width of discharge-tubes are not to be referred alone to the different temperatures of the gases, but depend essentially upon the amounts of electricity the passage of which conditions the oscillatory motions of the rther envelopes of every individual atom or molecule.

By means of such calorimetric measurements we might indeed succed in determining the quantities of heat which are necessary in order so to alter the state of the molecules and atoms that the band spectrum shall change into the line spectrum ; or, in other words, if we adopt the views developed in the former paper, we must be able to ascertain the amount of heat which is set free at the formation of the molecule of a simple body out of its atoms.

I shall shortly communicate something further upon these subjects.

Leipzig, January 1879.

XLI. On the Determination of the Variation of the Thermal Conductivity of Metals with Temperature, by means of the permanent Curve of Temperature along a uniform thin Rod heated at one end. By OLIver J. Lodge, D.Sc., Lecturer on Applied Mathematics and Mechanics at University College, London.

[Concluded from p. 211.]

Introduction of the experimental Values of the Variables into Equation (3) and the first Integration of it.

16. WHAT wo have accomplished so far is:- the writing of the fundamental equation (1) by help of equation (2) in the form (3), which involves the ratio of rate of cooling $\dot{\theta}$ to thermometric conductivity $\frac{k}{c \rho}$; and then the expression of these two quantities as functions of the temperature-the one as a complex function (5), the other as an inverse linear function (4). The latter contains Centigrade temperature $t$; but if we reckon temperature from the temperature of the enclosure $v_{0}$ instead of from the Centigrade zero, it will only affect the value of the constant $b$. So writing $v_{0}+b-274=m$, we get (4) in the form

$$
\frac{k}{c \rho}=\frac{\mathrm{A}}{m+\theta}=\frac{m k_{0}}{c_{0} \rho_{0}(m+\theta)} . \quad \text {. . . }
$$

